\title{
Efficacy of daiokanzoto in chronic constipation refractory to first-line laxatives
}

\author{
TATSUYA HIROSE $^{1,2}$, YASUTAKA SHINODA ${ }^{1,2}$, AYA YOSHIDA $^{1}$, MACHIKO KURIMOTO $^{1}$, KOUKI MORI $^{1}$, \\ YUKI KAWACHI $^{1}$, KOUJI TANAKA ${ }^{1}$, ATSUKO TAKEDA ${ }^{1}$, TOMOAKI YOSHIMURA $^{1,2}$ and TADASHI SUGIYAMA ${ }^{2}$ \\ ${ }^{1}$ Department of Pharmacy, Ogaki Municipal Hospital, Ogaki-shi, Gifu 503-8502; ${ }^{2}$ Laboratory of Pharmacy \\ Practice and Social Science, Gifu Pharmaceutical University, Gifu-shi, Gifu 501-1196, Japan
}

Received August 2, 2016; Accepted September 2, 2016

DOI: $10.3892 /$ br.2016.754

\begin{abstract}
There are only a few treatment options for constipation and limited evidence of suitable treatments. Daiokanzoto (DKT) is a Kampo medicine often used clincally to treat constipation. DKT is a laxative used predominantly in Japan; however, clinical data on its efficacy and safety is lacking. Patients who used DKT, but were intolerant to either magnesium oxide ( $\mathrm{MgO} ; \mathrm{MgO}$ group; $\mathrm{n}=16$ ) or senna extract (Senna group; $n=26$ ) were included in the present study. The frequencies of their bowel movements were compared during the 1 week prior to and following DKT administration. Within 24 hours after DKT administration, $93.8 \%$ of the patients in the $\mathrm{MgO}$ group evacuated their bowels. The median bowel movement frequency 1 week prior to DKT administration was 2.5 and 1 week after DKT administration was significantly increased to 7.5. In the Senna group, within $24 \mathrm{~h}$ of DKT administration, $80.8 \%$ of the patients evacuated their bowels. The median bowel movement frequency 1 week prior to the DKT treatment was 2.0, which significantly increased to 8.5 1 week after the administration of DKT. The adverse events from DKT treatment were mild and controllable.
\end{abstract}

\section{Introduction}

Constipation can contribute to health care costs and cause a decline in work productivity and the quality of life, as well as result in disability (1). Therefore, an effective treatment for constipation is important; however, only a few treatment options exist for constipation and there is limited evidence of suitable treatments.

Daiokanzoto (DKT) is a Kampo medicine often used clinically to treat constipation. DKT is composed of rhubarb and glycyrrhiza. Sennoside A is the active ingredient in DKT

Correspondence to: Mr. Tatsuya Hirose, Department of Pharmacy, Ogaki Municipal Hospital, 4-86 Minaminokawa, Ogaki-shi, Gifu 503-8502, Japan

E-mail: h.kanon0827@gmail.com

Key words: daiokanzoto, constipation, $\mathrm{MgO}$, Senna, Sennoside A responsible for its effects in constipation. However, DKT has demonstrated efficacy in patients with constipation who were intolerant to treatment with senna extract. According to the guidelines set by Lindberg et al (2), senna extract is recommended for the treatment of constipation. Magnesium oxide $(\mathrm{MgO})$ is commonly used as an osmotic laxative (3). Senna extract and $\mathrm{MgO}$ are therefore used as first-line treatments in numerous cases of constipation; however, patients who were intolerant to these two common laxatives were encountered. Since there is limited information on other laxatives, it is difficult to effectively treat such patients. Therefore, the present study examined the laxative effects of DKT in patients intolerant to the first-line treatments.

\section{Materials and methods}

Background. The present study was approved by the Ogaki Civilian Hospital Ethics Committee and was performed at Ogaki Municipal Hospital (Ogaki, Japan) between 1st May 2012 and 30th April 2015. Patients who used DKT, but were intolerant to either $\mathrm{MgO}$ ( $\mathrm{MgO}$ group) or senna extract (Senna group) were included in the present study. Patients were administered either $\mathrm{MgO}$ tablets or senna extract tablets for 1 week prior to the initiation of DKT treatment.

The present study retrospectively reviewed the following details of the patients from the electronic medical records: Age, height, weight, dose of DKT, concomitant medications and medical history. The increased total bilirubin (T-Bil) and blood urea nitrogen (BUN) levels were also recorded, as well as the serum levels of aspartate aminotransferase (AST), alanine transaminase (ALT), creatinine (Cre), $\mathrm{Na}, \mathrm{K}$ and $\mathrm{Cl}$. Other data that was deemed relevant was also recorded.

Comparison of the effects of DKT in the $\mathrm{MgO}$ and Senna groups. From the medical records of the patients, the present study obtained and compared the frequencies of their bowel movements during the 1 week prior to and following DKT administration.

Adverse events from DKT administration. The present study investigated the incidence of adverse events following treatment with DKT. The predominant adverse events were diarrhea and abdominal pain, which were evaluated using the Common 
Table I. Baseline characteristics of the patients.

\begin{tabular}{lcc}
\hline Characteristics & MgO resistance group (n=16) & Senna resistance group (n=26) \\
\hline Median age, years (interquartile range) & $71(65-77)$ & $72(68-78)$ \\
No. of males & 11 & 14 \\
No. of females & 5 & 12 \\
Median eight, kg (interquartile range) & $53(49-64)$ & $51(42-60)$ \\
Median height, cm (interquartile range) & $160(154-166)$ & $157(151-163)$ \\
Median days since last bowel movement & $3.5(2-6)$ & $4.0(2-6)$ \\
(interquartile range) & & \\
\hline
\end{tabular}

Table II. Clinical laboratory data in the $\mathrm{MgO}$ group.

\begin{tabular}{|c|c|c|c|c|}
\hline \multirow[b]{2}{*}{ Median levels } & \multicolumn{3}{|c|}{$\mathrm{MgO}$ resistance group } & \multirow[b]{2}{*}{ P-value } \\
\hline & $\begin{array}{c}\text { Prior to } \\
\text { administration }\end{array}$ & $\begin{array}{l}\text { Administered } \\
3 \text { days after }\end{array}$ & $\begin{array}{l}\text { Administered } \\
1 \text { week after }\end{array}$ & \\
\hline $\mathrm{Na}, \mathrm{mEq} / \mathrm{l}$ (interquartile range) & $136.5(135.75-139.25)$ & $136(135.5-139)$ & $137(136.5-138)$ & 0.618 \\
\hline $\mathrm{K}, \mathrm{mEq} / \mathrm{l}$ (interquartile range) & $4.25(4.075-4.5)$ & $4.4(4.1-4.55)$ & $4.3(4.1-4.45)$ & 0.846 \\
\hline $\mathrm{Cl}, \mathrm{mEq} / \mathrm{l}$ (interquartile range) & $102.5(99.75-106)$ & $104(100.5-106)$ & $104(102-105.5)$ & 0.88 \\
\hline AST, IU/l (interquartile range) & $20.5(14.75-26.75)$ & $18.5(12.5-26.75)$ & $18(13.5-25)$ & 0.782 \\
\hline ALT, IU/l (interquartile range) & $19(13.75-26)$ & $18(15.5-32.5)$ & $15(11-30)$ & 0.607 \\
\hline T-Bil, mg/dl (interquartile range) & $0.6(0.525-0.775)$ & $0.6(0.5-0.8)$ & $0.5(0.4-0.6)$ & 0.0861 \\
\hline BUN, mg/dl (interquartile range) & $17.1(14.225-19.725)$ & $16.7(14.625-22.1)$ & $14.5(12.8-18.35)$ & 0.119 \\
\hline Cre, mg/dl (interquartile range) & $0.625(0.59-0.9325)$ & $0.705(0.6125-0.9925)$ & $0.72(0.64-0.92)$ & 0.185 \\
\hline
\end{tabular}

Table III. Clinical laboratory data of the Senna group.

\begin{tabular}{lccc}
\hline & \multicolumn{3}{c}{ Senna resistance group } \\
\cline { 2 - 4 } Median levels & $\begin{array}{c}\text { Prior to } \\
\text { administration }\end{array}$ & $\begin{array}{c}\text { Administered } \\
3 \text { days after }\end{array}$ & $\begin{array}{c}\text { Administered } \\
1 \text { week after }\end{array}$ \\
\hline Na, mEq/l (interquartile range) & $138(135.25-140)$ & $138(134-140)$ & $138.5(137.75-141)$ \\
K, mEq/l (interquartile range) & $4.1(3.725-4.475)$ & $4.1(3.8-4.6)$ & $4.1(3.575-4.55)$ \\
Cl, mEq/l (interquartile range) & $101.5(100-105.75)$ & $102(99-106)$ & $103.5(101.5-105.25)$ \\
AST, IU/l (interquartile range) & $23(19-33.75)$ & $20(15-34)$ & 0.127 \\
ALT, IU/l (interquartile range) & $21(12.75-32.75)$ & $18(12-28)$ & 0.565 \\
T-Bil, mg/dl (interquartile range) & $0.5(0.4-0.8)$ & $0.5(0.375-0.625)$ & $0.4(0.3-0.7)$ \\
BUN, mg/dl (interquartile range) & $18.6(14.7-23)$ & $15.3(10.9-22.4)$ & $15(9.7-19.2)$ \\
Cre, mg/dl (interquartile range) & $0.72(0.5525-0.945)$ & $0.64(0.53-0.86)$ & $0.62(0.51-0.88)$ \\
\hline
\end{tabular}

Terminology Criteria for Adverse Events (version 4.0; http://evs. nci.nih.gov/ftp1/CTCAE/About.html). In addition, the presents study also compared the changes in clinical laboratory data prior to, 3 days and 1 week after DKT administration.

Statistical analysis. Statistical analyses were performed using EZR software v1.26 (4). The effects of DKT in the groups were compared using Wilcoxon signed-rank test at a significance level of 5\%. Differences in the laboratory test results, 3 days and 1 week after DKT administration, were evaluated using the Friedman test. The significance level was also set at 5\%.

\section{Results}

Background. A total of 16 patients (11 male and 5 female) were enrolled into the $\mathrm{MgO}$ group and their median age was 71 years (interquartile range, 65-77 years). A total of 26 patients (14 male and 12 female) were enrolled in the Senna group and their 


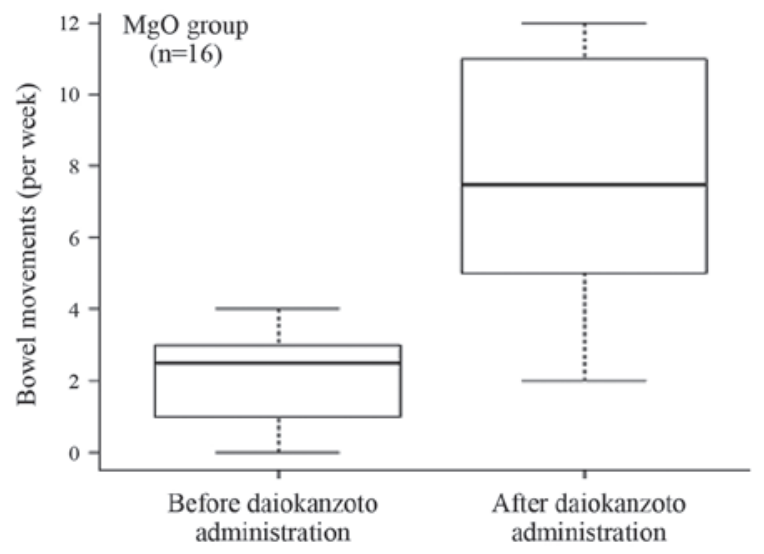

Figure 1. Number of bowel movements per week in the $\mathrm{MgO}$ group. The median bowel movement frequency 1 week prior to DKT administration was 2.5 (interquartile range, 1-3). However, 1 week after DKT administration, the frequency significantly $(\mathrm{P}<0.001)$ increased to 7.5 (interquartile range, 5-11). DKT, daiokanzoto.

median age was 72 years (interquartile range, $68-78$ years). In both the $\mathrm{MgO}$ and Senna groups, the last bowel movements were 3.5 (interquartile range, 2-6 days) and 4.0 days (interquartile range, 2-6 days), respectively, prior to DKT administration. Baseline characteristics of the patients are shown in Table I.

Effect of DKT in the $\mathrm{MgO}$ group. Following the administration of DKT, $93.8 \%$ of patients in the $\mathrm{MgO}$ group evacuated their bowels within $24 \mathrm{~h}$. The median bowel movement frequency 1 week prior to DKT administration was 2.5 (interquartile range, 1-3). However, 1 week after DKT administration, the frequency significantly $(\mathrm{P}<0.001)$ increased to 7.5 (interquartile range, 5-11), as shown in Fig. 1.

Effect of DKT in the Senna group. Following the administration of DKT, $80.8 \%$ of the patients in the Senna group evacuated their bowels within $24 \mathrm{~h}$. The median bowel movement frequency 1 week prior to DKT treatment was 2.0 (interquartile range, $1-4)$, which significantly $(\mathrm{P}<0.001)$ increased to 8.5 (interquartile range, 7-14) 1 week after the administration of DKT (Fig. 2).

Adverse events from DKT administration. In the Senna group, there were four cases of diarrhea (15.4\%) and one case of abdominal pain (3.8\%). Both adverse events were mild (Grade 1) in each group of patients.

In the $\mathrm{MgO}$ group, no statistically significant differences were observed among the clinical laboratory data obtained prior to, 3 days and 1 week after DKT administration (Table II). By contrast, in the Senna group, the differences among the levels of ALT prior to, 3 days and 1 week after DKT administration were statistically significant $(\mathrm{P}<0.05$ for each pair compared) (Table III). It was observed that ALT decreased with increasing duration following treatment with DKT.

\section{Discussion}

It is known that $\sim 14 \%$ of the global adult population suffer from chronic constipation (5). In a previous systematic review, it was stated that chronic constipation lowers the quality of

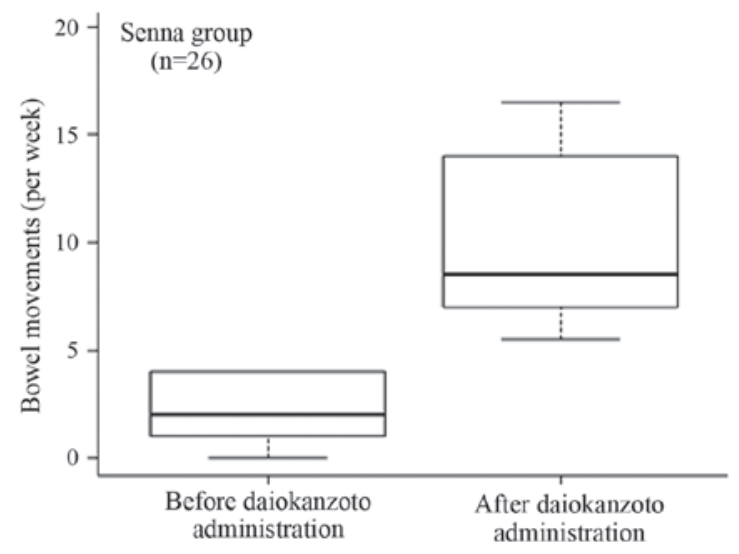

Figure 2. Number of bowel movements per week in the Senna group. The median bowel movement frequency 1 week prior to the DKT treatment was 2.0 (interquartile range, $1-4)$, which significantly $(\mathrm{P}<0.001)$ increased to 8.5 (interquartile range, 7-14) 1 week after the administration of DKT. DKT, daiokanzoto.

life (5). In addition, individuals with chronic constipation have an increased risk of developing colon cancer. The risk increases with an increasing degree of constipation (6).

In a previous study, it was observed that preventing constipation improved multi-organ failure in critically ill patients (7). Therefore, it is important that evidence of the clinical effects of the treatment of constipation are accumulated to improve the care of patients. Usually, clinical treatment of constipation with a single laxative is ineffective. DKT is a laxative predominantly used in Japan; however, clinical data on its efficacy and safety is lacking.

In the present study, DKT was considered beneficial in constipation refractory to $\mathrm{MgO}$ treatment. Although $\mathrm{MgO}$ is often prescribed for constipation, it is not effective in certain individuals, particularly elderly patients. $\mathrm{MgO}$ is an osmotic laxative; it is converted into magnesium carbonate in the intestine, which inhibits water reabsorption from the intestine. As a result, the volume of intestinal contents increases, which stimulates motility of the intestinal tract, thereby facilitating defecation. Elderly patients have reduced intestinal motility, which results in reduced bowel movements. Therefore, $\mathrm{MgO}$ has minimal efficacy in treating constipation in the elderly.

The mechanism by which sennoside A in DKT improves constipation is via enhanced peristalsis. A senna extract tablet contains $6.8 \mathrm{mg}$ sennoside A. In the present study, two senna extract tablets (13.6 mg sennoside A) were administered to the patients. By contrast, one package of DKT contains $2.9 \mathrm{mg}$ sennoside A. In the present study, patients were administered three packages of DKT (8.7 mg sennoside A). Although the administered DKT contained a lesser quantity of sennoside A, it was observed that DKT was more effective compared with the senna extract tablets, regarding the frequency of bowel movements.

The predominant components of rhubarb and glycyrrhiza are sennoside A and glycyrrhizin, respectively. Sennoside A is metabolically activated to rheinanthrone, which is responsible for the laxative action of sennoside A (8-10). Glycyrrhiza contains liquiritin, which has been reported to promote the metabolic activation sennoside A into rheinanthrone $(11,12)$. In addition, Takayama et al (13) reported that rhein in 
rhubarb promotes the metabolic activation sennoside A to rheinanthrone.

Although patients exhibited inadequate bowel movements after taking senna extract tablets, switching from the senna extract tablets to DKT was effective in relieving constipation. It was therefore hypothesized that reason for this was the presence of glycyrrhiza and rhubarb in the DKT.

The adverse events from DKT treatment were mild and controllable. Therefore, properly adjusting the doses of DKT according to patients' requirements may suitably reduce the occurrence of adverse events.

The results from the present study indicated that DKT may be a suitable second-line treatment for chronic constipation, particularly in elderly patients.

\section{References}

1. Sun SX, Dibonaventura M, Purayidathil FW, Wagner JS, Dabbous $\mathrm{O}$ and Mody R: Impact of chronic constipation on health-related quality of life, work productivity, and healthcare resource use: An analysis of the National Health and Wellness Survey. Dig Dis Sci 56: 2688-2695, 2011.

2. Lindberg G, Hamid SS, Malfertheiner P, Thomsen OO, Fernandez LB, Garisch J, Thomson A, Goh KL, Tandon R, Fedail S, et al; World Gastroenterology Organisation: World Gastroenterology Organisation global guideline: Constipation - a global perspective. J Clin Gastroenterol 45: 483-487, 2011.

3. Vazquez Roque $M$ and Bouras EP: Epidemiology and management of chronic constipation in elderly patients. Clin Interv Aging 10: 919-930, 2015.
4. Kanda Y: Investigation of the freely available easy-to-use software 'EZR' for medical statistics. Bone Marrow Transplant 48: 452-458, 2013.

5. Gürsen C, Kerem Günel M, Kaya S, Kav T and Akbayrak T: Effect of connective tissue manipulation on symptoms and quality of life in patients with chronic constipation: A randomized controlled trial. J Manipulative Physiol Ther 38: 335-343, 2015.

6. Guérin A, Mody R, Fok B, Lasch KL, Zhou Z, Wu EQ, Zhou W and Talley NJ: Risk of developing colorectal cancer and benign colorectal neoplasm in patients with chronic constipation. Aliment Pharmacol Ther 40: 83-92, 2014.

7. de Azevedo RP, Freitas FG, Ferreira EM, Pontes de Azevedo LC and Machado FR: Daily laxative therapy reduces organ dysfunction in mechanically ventilated patients: A phase II randomized controlled trial. Crit Care 19: 329, 2015.

8. Sasaki K, Yamauchi K and Kuwano S: Metabolic activation of sennoside A in mice. Planta Med 37: 370-378, 1979.

9. Kobashi K, Nishimura T, Kusaka M, Hattori M and Namba T: Metabolism of sennosides by human intestinal bacteria. Planta Med 40: 225-236, 1980

10. Lemli J and Lemmens L: Metabolism of sennosides and rhein in the rat. Pharmacology 20 (Suppl 1): 50-57, 1980.

11. Matsui E, Takayama K, Sato E and Okamura N: The influence of glycyrrhiza and antibiotics on the purgative action of sennoside a from Daiokanzoto in mice. Biol Pharm Bull 34: 1438-1442, 2011.

12. Takayama K, Matsui E, Kobayashi T, Inoue H, Tsuruta $\mathrm{Y}$ and Okamura N: High-performance liquid chromatographic determination and metabolic study of sennoside a in daiokanzoto by mouse intestinal bacteria. Chem Pharm Bull (Tokyo) 59: 1106-1109, 2011.

13. Takayama K, Morita T, Tabuchi N, Fukunaga M and Okamura N: The effect of anthraquinones in daiokanzoto on increasing the synthesis of sennoside A-metabolic enzyme derived from bifidobacteria. J Trad Med 30: 215-220, 2013. 